\title{
EM DEFESA DAS REVOLUÇÕES: CAPITALISMO E ESCRAVIDÃO NA FORMAÇÃO DO MUNDO CONTEMPORÂNEO
}

BLACKBURN, Robin. The American Crucible: Slavery, Emancipation and Human Rights. Londres: Verso, 2011. 498 p.

$E_{\mathrm{m} \text { janeiro de 2012, Barbara Solow }}$ e David Brion Davis ocuparam as páginas da prestigiosa The New York Review of Books para discutir um assunto que faria pouca gente arquear as sobrancelhas no Brasil. Solow tinha considerado errada a crença de Davis na morte da famosa hipótese de Eric Williams sobre o declínio econômico do sistema escravista britânico na antevéspera de sua abolição. Davis respondeu que uma "vasta montanha de provas empíricas" solapava a hipótese de Williams, como se podia ler em toda a obra de Seymour Drescher, "a maior autoridade mundial sobre o movimento abolicionista britânico". ${ }^{1}$

$\mathrm{O}$ entrevero de dois autores internacionalmente consagrados na área

The New York Review of Books, "The British and the Slave Trade", 12 de janeiro de 2012. Disponível em <http:// www.nybooks.com/articles/archives/ 2012/jan/12/british-slave-trade $>$. de história da escravidão sobre o legado de Eric Williams pode parecer estranho para um leitor do Brasil. Nas academias do país, Williams atravessou o mesmo percurso que a chamada "escola sociológica" de São Paulo, isto é, foi submetido à sucessão geracional de visões historiográficas antagônicas, passando rapidamente de autoridade discursiva a discurso desautorizado. No lugar de debates contínuos, revisão crítica sistemática e reformulação de ideias antigas sobre bases parcialmente novas, Eric Williams foi lançado para o almoxarifado da historiografia. Esse procedimento, que não se aplica só aos casos mencionados e cujas causas merecem um estudo à parte, tem seu preço.

O livro que Robin Blackburn lançou em 2011, The American Crucible, não existiria sem o prolongado debate acadêmico anglo-saxão sobre a herança intelectual de Eric Williams. 
A obra é a mais recente da série que o autor vem dedicando à análise dos sistemas escravistas no continente americano e que inclui The Overthrow of Colonial Slavery (1988) e The Making of New World Slavery (1997) - ambos com tradução para o português (respectivamente, 2002 e 2003, pela Editora Record). Suas ideias centrais são simples e audaciosas. Por um lado, a escravidão negra nas Américas teria sido uma instituição fundamental para a formação dos dois pilares do mundo contemporâneo: a Revolução Industrial, no plano econômico, e os direitos humanos, no plano político. Por outro, o capitalismo industrial teria gerado crises capazes de pôr um fim à escravidão negra. O termo que sintetiza o título da narrativa explicita o nexo entre esses dois polos. "Crucible" pode significar tanto "cadinho", isto é, pote que, fundindo elementos de origem diversa, gera matéria nova, como também "provação", "penúria”, “calvário". Ao sintetizar seu livro com um substantivo polissêmico que une criação e sofrimento, Blackburn sugere que a montagem do capitalismo contemporâneo não pode ser desvinculada do processo de alienação, violência, martírio e luta por que passaram os africanos e seus descendentes durante a ascensão e a queda do cativeiro nas Américas.

Blackburn retoma e desenvolve, com modificações, as relações con- traditórias entre escravidão e capitalismo que Eric Williams estabeleceu em Capitalism and Slavery (1944). A particularidade de sua análise está em substituir a noção de declínio pela de destruição do cativeiro. O capitalismo teria estimulado o surgimento de tensões de classe e de condições revolucionárias que fizeram a mediação necessária entre poderosas estruturas objetivas de produção e a abolição do cativeiro. A pegada diferente tem implicação historiográfica. $\mathrm{O}$ valor das revoluções e, nelas, da ação escrava aparece em The American Crucible como um tributo intelectual às obras de C. L. R. James e de W. E. B. Du Bois. ${ }^{2}$

A trinca Williams-James-Dubois, feita de autores negros, foi escolhida a dedo por Blackburn. Desde a década de 1970, parte da historiografia anglo-saxã e mundial vem narrando a crise da escravidão nas Américas de um modo que prescinde de suas colocações. Sendo essa vertente encabeçada por Drescher, "a maior autoridade mundial" na história do abolicionismo, o gesto de Blackburn revela o desejo de contrapropor uma narrativa

\footnotetext{
C. L. R. James, Os jacobinos negros: Toussaint L'Ouverture e a revolução de Saint-Domingue [1 $1^{\mathrm{a}}$ ed. em inglês, 1938]. São Paulo: Boitempo Editorial, 2000; W. E. B. Du Bois, Black Reconstruction in America: An Essay Toward the History of the Part Which Black Folk Played in the Attempt to Reconstruct Democracy in America, 1860-1880, Nova York: Russell \& Russell, 1956 [orig. 1935].
} 
da modernidade em geral e da escravidão nas Américas em particular.

\section{I}

Drescher lançou Econocide (1977) para desferir um ataque sem concessões à obra de Williams, que oferecia aos historiadores a mais bem acabada interpretação marxista das conexões entre cativeiro, abolição e capitalismo no Império britânico. Em Capitalism and Slavery, Williams aduzira duas teses opostas, mas interligadas, sobre seu objeto de estudo: (i) o sistema escravista nas Antilhas britânicas fornecera produtos agrícolas, capital e mercado consumidor aos manufatureiros metropolitanos, estimulando o surgimento da Revolução Industrial; (ii) com a Independência dos Estados Unidos (1776), o Caribe britânico entrou em declínio e caiu refém do movimento abolicionista. Em Econocide, Drescher procurou enterrar o livro e suas hipóteses. Os dados que apresentou indicavam a rentabilidade crescente das plantations, o incremento absoluto da produção açucareira e a maior relevância do Caribe britânico no conjunto das importações e das exportações inglesas entre 1776 e 1806 . O autor alegou haver uma radical disjunção entre desempenho da economia colonial e ascensão do abolicionismo metropolitano. ${ }^{3}$

Seymour Drescher, Econocide: British Slavery in the Era of Abolition (1977), Chapel Hill: The University of North Caro-
Num artigo originalmente publicado em Slavery and Abolition, em 1986, Drescher constatou que Econocide vinha estimulando uma série de estudiosos a "encontrarem uma nova base ideológica para o abolicionismo". ${ }^{4}$ Não é o caso de analisar, aqui, os trabalhos daqueles que exemplificam a frase - David Brion Davis, Howard Temperley, Thomas Haskell, John Ashworth, alguns dos quais foram incluídos no The Antislavery Debate (1992), editado por Thomas Bender, ou a pesquisa de Kwame Anthony Appiah sobre revoluções morais -, dado que o próprio Drescher sintetizou sua resposta ao problema. Em livro recente ${ }^{5}$ ponto de chegada de uma longa e coerente agenda de pesquisa, seu raciocínio se desenvolve em dois passos. Como as plantations no Caribe britânico cresciam em termos absolutos para os proprietários e em termos relativos para o conjunto da

\footnotetext{
lina Press, 2010. Seu estudo tinha sido precedido, na crítica a Williams, por Roger Anstey, The Atlantic Slave Trade and British Abolition, 1760-1810, Londres: Macmillan, 1975. A edição mais recente do livro de Williams é Capitalismo e escravidão, São Paulo: Companhia das Letras, 2012.

4 Seymour Drescher, "The Decline Thesis of British Slavery since Econocide", in Drescher, From Slavery to Freedom: Comparative Studies in the Rise and Fall of Atlantic Slavery (Nova York: New York University Press, 1999), p. 110.

5 Seymour Drescher, Abolition: A History of Slavery and Antislavery, Cambridge: Cambridge University Press, 2009, esp.
} pp. 115-266. 
economia imperial britânica na virada do XVIII para o XIX, a única explicação plausível para o seu colapso se encontraria no campo político (passo 1). O abolicionismo, inicialmente restrito a um grupo inexpressivo, só conseguiu influenciar a agenda de governo porque a Grã-Bretanha possuía a mais densa esfera pública do planeta, capaz de reverberar e guiar a ação de seus governantes. Ao dominar esse espaço, o abolicionismo dominou o governo (passo 2). Assim na supressão do tráfico negreiro (1807), assim também na abolição do cativeiro (1833-1838). A crise da escravidão nas Américas não resultaria do eixo de forças contraditórias que a Era das Revoluções liberou. Seria, antes, efeito da mobilização civil pacífica que os abolicionistas anglo-saxões souberam conduzir.

\section{II}

Contra o pano de fundo esboçado acima é que a história contada em The American Crucible ganha sentido específico. O livro está dividido em quatro partes. Na primeira e na segunda ("Empires and Plantations" e "The Subversive Boom"), Blackburn retoma, com incorporação da bibliografia mais recente, as ideias formuladas em The Making of New World Slavery. Na terceira ("The Haitian Pivot") revisita o argumento de The Overthrow of Colonial Slavery, focando na Revolução Haitiana e en- gajando-se no diálogo com Drescher. $\mathrm{Na}$ última ("The Age of Abolition") aborda a ascensão e a queda dos regimes escravistas oitocentistas (no sul dos EUA, nas colônias espanholas de Cuba e Porto Rico e no Império do Brasil), assunto ao qual promete voltar num livro futuro, e discute o legado da emancipação escrava para a formulação da doutrina dos direitos humanos, confrontando mais uma vez Drescher.

\section{III}

Para Blackburn, a montagem da escravidão negra nas Américas durante o período colonial não pode ser unificada em uma estrutura histórica singular. Seguindo o que já escrevera em The Making, a América teria conhecido dois tipos de sistemas escravistas: o hispânico, que chamou de barroco, e o dos demais impérios, que chamou de mercantil. No Império espanhol, a instituição nunca deixou de ser periférica. Quando, entre 1520 e 1550, a conquista da Tierra Firme alterou a natureza da administração colonial, Madri investiu na extração de metais preciosos do ultramar para atender ao pagamento de tropas no cenário de guerra europeu e equilibrar a balança comercial com o Oriente, aproveitando as redes de extração tributária dos populosos impérios asteca e inca e montando um sistema de frotas que, embora caro e lento, se ajustava ao deslocamento dos 
metais preciosos. A escravidão, sem vínculo direto com o centro da economia mundial nem transporte adequado para itens de consumo em massa, se reduziu, em geral, a um papel ancilar nas minas ou se concentrou nas cidades portuárias. Por causa das Siete Partidas, conjunto de normas jurídicas reunidas no século XIII que permitia ao escravo o direito ao pecúlio e à compra de sua alforria, um alto índice de manumissão caracterizou a "escravidão barroca". E, como a noção de limpeza de sangue não filtrava os súditos com rigor, a população negra e mulata livre gozou razoável mobilidade social nos limites do Antigo Regime hispânico.

A revolução açucareira em Pernambuco, Bahia, Barbados, Jamaica, Martinica, Guadalupe e SaintDomingue (futuro Haiti), bem como o cultivo de tabaco e arroz na América continental britânica, compuseram a segunda estrutura do sistema escravista nas Américas. O que teria unificado espaços tão distantes numa mesma temporalidade? A resposta estaria em sua articulação à expansão do mercado consumidor europeu, cujo impulso inicial Blackburn, baseandose em Robert Brenner, identifica na revolução agrária inglesa do século XVI. Graças à mercantilização das relações sociais no noroeste europeu, produtores da América em geral e do Império britânico em particular contaram com mercado metropolitano di- nâmico, amplos canais de crédito e constante inovação técnica no processo produtivo, elementos que, engatados no tráfico negreiro transatlântico, permitiram a consolidação de sociedades escravistas sobre a base do regime de plantation, com baixas taxas de alforria, pequena margem para mobilidade vertical dos ex-escravos e extrema racialização do trabalho. Pernambuco e Bahia, como se vê, não se encaixam perfeitamente nessa descrição. Além de sua ligação apenas indireta com as inovações ocorridas no sistema econômico do noroeste europeu, as relações entre senhores e escravos na colônia portuguesa eram moldadas por um enquadramento jurídico semelhante ao das Siete Partidas. Se definisse uma ruptura entre a escravidão brasileira e a caribenha, Blackburn daria mais sentido à sua constatação de que a única vantagem comparativa que os luso-brasileiros possuíam na competição com os produtores antilhanos estava no volumoso tráfico negreiro, que lhes entregava cativos pela metade do preço pago por seus concorrentes.

\section{IV}

A escravidão mercantil das Américas teria sido um grande estímulo à decolagem da industrialização na GrãBretanha? A relação de causa e efeito entre ambas, basicamente a tese I de Williams, foi frequentemente rejeitada por historiadores nas décadas 
de 1960 e 1980, justamente quando Drescher refutou sua tese II. Refinando o modelo de Williams, Blackburn aferiu a contribuição atlântica para a Revolução Industrial mapeando o mercado consumidor das exportações britânicas nas plantations americanas e na África, os lucros dos negociantes e proprietários escravistas, o fornecimento de matérias-primas à metrópole, o papel da escravidão na formação de um mercado de capitais e seu estímulo à adoção na Europa de novos padrões de consumo e de trabalho (o que Jan de Vries chamou de "revolução industriosa"). Em suma, retoma argumentos já feitos em The Making, com perdas por reduzir o uso dos dados estatísticos e ganhos por encarar a bibliografia recente sobre o tema, da qual vale destacar as obras de Kenneth Pomeranz, Joseph Inikori e Findlay \& O'Rourke. ${ }^{6}$

Segundo o argumento geral do livro, o mundo que a Revolução Industrial criou não impôs limites econômicos à escravidão negra. Como

6 Kenneth Pomeranz, The Great Divergence: China, Europe, and the Making of the Modern Economy, Princeton: Princeton University Press, 2000; Joseph E. Inikori, Africans and the Industrial Revolution in England: A Study in International Trade and Economic Development, Cambridge: Cambridge University Press, 2002; Ronald Findlay \& Kevin H O'Rourke, Power and Plenty: Trade, War, and the World Economy in the Second Millenium, Princeton: Princeton University Press, 2007.
Blackburn consegue, então, rearticular economia, escravidão e abolicionismo no início do século XIX? Sua resposta é formulada em dois movimentos, que retomam uma linha de raciocínio exposta em The Overthrow of Colonial Slavery. No primeiro, ele evoca a Independência dos Estados Unidos. O arrojo dos patriotas em 1776 só fora possível graças à consolidação do mercado comum do Atlântico norte, que interligava a economia continental, as Antilhas europeias e os portos negreiros da Europa. Incorporando o ótimo livro $\mathrm{Mo}$ ral Capital (2006), de Christopher Brown, Blackburn entende que a Independência concitou as unidades do norte do novo país à emancipação gradual dos escravos e desaguou, em Londres, numa crise ideológica capaz de arrastar a elite política para um amplo reformismo das instituições imperiais, entre elas o tráfico negreiro. Sem essa disposição da elite política, a esfera pública e os meios de propaganda que Drescher estudou não teriam dado à cruzada moral do abolicionismo a amplitude necessária para chegar com expressividade ao Parlamento. E mesmo assim os campeões da causa acabaram frustrados. Sem alianças amplas e uma crise estrutural profunda, suas chances eram escassas. Noutros termos, sem revolução, nada seria feito. 
V

Em seu segundo movimento Blackburn dá o devido peso à Revolução de Saint-Domingue (17911804) na confecção da lei que suprimiu o tráfico negreiro para o Império britânico (1807). A composição demográfica da colônia francesa, a exploração intensa do trabalho, as lutas intestinas entre brancos e proprietários de cor, a experiência militar e revolucionária dos colonos na Guerra dos Sete Anos e na Guerra de Independência dos Estados Unidos, as tensões que a Coroa agravou ao querer restringir a soberania doméstica dos senhores ou criar as milícias de cor no ultramar, os conflitos entre proprietários brancos e negociantes girondinos, as invasões da ilha por tropas britânicas e espanholas, todos esses elementos são mobilizados para explicar a evolução excepcional de uma revolta de escravos que, no início (1791), "não estavam comprometidos com o final da escravidão" (p. 184), para a sublevação revolucionária da ordem social e, por fim, para os decretos de 1793 e de 1794 que aboliram o instituto do cativeiro nas Antilhas francesas. No lustro subsequente (1794-1798), a conquista jurídica saltou para a esfera social. As guerras de resistência contra expedições escravistas da Grã-Bretanha tornaram a defesa da liberdade atributo de todos os grupos da colônia. Quando Napoleão quis reinstituir ali o ca- tiveiro em 1802 e 1803, viu suas tropas acachapadas pela resistência popular generalizada, e não por uma dúbia e cambiante elite política. $\mathrm{O}$ Haiti foi o primeiro país do Ocidente no qual a liberdade teria sido uma experiência universal. Para levar essa palma dourada, precisou passar por um sangrento processo revolucionário de treze anos (1791-1804), mais longo que o da própria França (17891798).

Segundo Blackburn, o nascimento do Haiti é o grande evento moldador do século XIX. As leis que surgiram no seio de suas lutas fornecem "aquelas raras ocasiões em que o texto pode definir o contexto e o subtexto, porque está estabelecendo um novo horizonte" (p. 191). O decreto de 16 de Pluviôse (4 de fevereiro) de 1794 ofereceu "um veredito sobre a instituição mais incisivo que qualquer outra declaração de direitos", isto é, a dos Estados Unidos (1776) e da própria França (1789).

Suas constituições ultrapassaram o conservadorismo da norte-americana e ajudaram a estabelecer no país uma "doutrina nova e muito incomum: a da igualdade racial" (p.208). A vitória dos revolucionários em 1804 animou a rearticulação do movimento abolicionista na metrópole inglesa e, ao riscar do mapa o grande produtor de açúcar de um império rival, aplanou o caminho para a supressão do tráfico negreiro britânico em 1807. 
Na esteira de Waterloo, o Tratado de Paris (1814) ainda previa restaurar o status colonial do Haiti e tolerar um tráfico negreiro para o Império francês por cinco anos. A enorme pressão abolicionista contra esse arranjo escravista permitiu que Napoleão, cortejando a opinião pública inglesa em seu governo dos 100 dias, decretasse o fim do comércio transatlântico de escravos. E deu força para que a diplomacia britânica, no Congresso de Viena, arrancasse de outros países a primeira declaração internacional antitráfico do Ocidente.

Blackburn conclui que o "impacto do antiescravismo" haitiano na radicalização da noção de "direitos do homem" (p. 197) e "na cultura política moderna” (p. 203) dificilmente pode ser exagerado. Em seu conjunto, essa interpretação ajusta contas com Drescher, bem como João Pedro Marques. Em "The Limits of Example", Drescher escrevera que a presença do Haiti fora da bacia caribenha era pequena. No Brasil, por exemplo, "seu impacto, como estímulo à emancipação ou à abolição do tráfico negreiro, parece irrisório, no máximo". ${ }^{7}$ Há, porém, outra forma de equacionar o problema.

\footnotetext{
Seymour Drescher, "The Limits of Example", in David Geggus (org.), The Impact of the Haitian Revolution in the Atlantic World (Chapel Hill: The University of North Carolina Press, 2001), pp. 10-4 (citação na p. 11); João Pedro Marques,
}

VI

No século XIX, o Ocidente assistiu não apenas à consolidação da Revolução Industrial, dos regimes representativos e de uma noção mais radical dos direitos do homem, mas também à expansão da escravidão negra no sul dos Estados Unidos, no Império do Brasil e nas colônias espanholas de Cuba e Porto Rico. Baseando-se em estudos de Rogers Smith, Joseph Fradera e Berbel, Marquese \& Parron, Blackburn afirma que a revolta no Haiti encorajou "os fazendeiros do Brasil, de Cuba e dos EUA a tomarem precauções e estabelecerem uma base social mais ampla" para seus regimes escravistas (p. 268), traduzida na construção de barreiras raciais mais rígidas nos EUA, na rejeição do liberalismo político pelos hacendados cubanos e na concepção de cidadania desracializada no Brasil. Nos três espaços, tais respostas, em que pesem suas diferenças, atenderam ao propósito comum de fortalecer a ordem social da escravidão num mundo em que o Haiti entrara no cálculo político dos estadistas.

Estados Unidos, Brasil e Cuba se entrelaçaram numa nova temporalidade da escravidão negra durante o

"Slave Revolts and the Abolition of Slavery: An Overinterpretation", in Seymour Drescher \& Peter C. Emmer (orgs.), Who Abolished Slavery? Slave Revolts and Abolitionism. A debate with João Pedro Marques (Nova York: Berghahn Books, 2010), pp. 3-92. 
século XIX. Diferentemente dos proprietários coloniais, seus produtores atuaram em mercados abertos que lhes impunham forte pressão competitiva, obrigando-os a ampliar continuamente a escala produtiva para manter a cabeça à tona d'água nos principais mercados consumidores do Atlântico Norte. Contaram com disponibilidade de terras férteis mais amplas que em Barbados, Martinica, Jamaica ou Saint-Domingue, sendo capazes de, mais cedo ou mais tarde, adotar ferrovias e atingir sucessivas rupturas de magnitude no patamar produtivo. Tiveram acesso a mercados de mão de obra escravizada mais volumosos que em qualquer período de tempo análogo nos séculos anteriores. Por fim, concentraram extremo poder político nos níveis local e nacional ou imperial, explorando "histórias de conspiração escrava" para "impor um regime ainda mais duro sobre os cativos" (p. 286). Num ensaio de 1988 e em escritos posteriores, Dale Tomich vem chamando essa temporalidade do cativeiro oitocentista, afinada com as demandas que $o$ mundo contemporâneo estava criando, de "segunda escravidão". Blackburn assimilou o termo, porém com liberdade.

Como é sabido, o conceito de "segunda escravidão" opera dentro de alguns pressupostos da perspectiva de economia-mundo de Immanuel Wallerstein e Giovanni Arrighi, se- gundo os quais o capitalismo é definido como um sistema econômico em que o capital é empregado, de maneira extremamente flexível, com a finalidade de sua autoexpansão. Nesses termos, a escravidão não aparece como unidade separada do capitalismo nem no plano da análise nem no da história. Mas Blackburn identifica o capitalismo com massificação produtiva e trabalho assalariado, na linha dos marxistas que segue (Williams, Brenner, Perry Anderson, Eric Hobsbawm). Sente-se, assim, à vontade para frisar diferenças materiais significativas entre os polos da escravidão e do capitalismo, atribuindo ao primeiro aspectos menos modernos: mercado interno relativamente modesto, mecanização extremamente seletiva, pouca flexibilidade do trabalho escravo, intensa dependência de crédito e transporte externos e menor capacidade institucional para reter a formação do capital que gera.

A linha de raciocínio de Blackburn não o leva a afirmar que o cativeiro oitocentista colapsou em razão de seus relativos limites econômicos, numa espécie de ampliação vulgar da tese II de Williams. Pelo contrário, tal como a guerra haitiana tinha sido o pivô da gênese da terceira estrutura histórica da escravidão nas Américas, apenas outra de proporções também gigantescas - a Guerra Civil (1861-65), nos Estados 
Unidos - pôde unir verticalmente escravos, pessoas livres de cor, trabalhadores brancos, imigrantes e nativos no movimento comum para destruir uma instituição que parecia inabalável. Sem as tensões de classe e, em seguida, a crise revolucionária de 1861 - que Blackburn vê como resultante do confronto de dois nacionalismos expansionistas concorrentes -, nem os limites econômicos da escravidão, nem a resistência dos cativos, nem a campanha moral dos abolicionistas teriam triunfado sobre o "slave power". Tal como no Haiti, a liberdade nos Estados Unidos nasceu do cruento aprendizado revolucionário. Influenciados pelo desfecho de 1865, Brasil e Cuba enfrentariam, a seu tempo, um processo semelhante ao norte-americano. No final do século, porém, os revolucionários dos três espaços acabaram revolucionados por uma nova conjuntura do capitalismo industrial, que empregou as ideias abolicionistas, numa das mais repugnantes ironias da história, para erguer o colonialismo na África e na Ásia. Descarnado das lutas de classe e da revolução, tal é o argumento de Blackburn, o abolicionismo é um esqueleto ideológico sem energia social transformadora.

\section{VII}

The American Crucible possui dimensão épica análoga ao tema que aborda, e sua leitura parcial pode levar a falsas impressões. O livro contém trechos que parecem depositar poder demiúrgico nas mãos dos atores sociais e outros que atribuem às forças de mercado um peso descomunal. Sua chave para compreender processos históricos, porém, ao eleger tensões de classe e crises conjunturais como instâncias mediadoras entre o tempo longo e o tempo curto da dinâmica social, desfaz os extremos aparentes. Se for entendido como uma narrativa que mobiliza Du Bois, James e Williams para rearticular política e economia, estrutura e ação humana, numa análise da escravidão negra destinada a questionar a abordagem que vem sendo consagrada por Seymour Drescher, The American Crucible se torna um livro poderoso não apenas para aquilatar o valor das experiências revolucionárias no passado (cadinho), mas também para medir o limite das democracias de mercado no presente (calvário). Noutros termos, o crucible e o crucible do mundo contemporâneo.

Tâmis Parron tamisparron@yahoo.com Universidade de São Paulo 